\title{
Qualitative interpretation method of water flooding in independent off surface reservoir of Lamadian Oilfield
}

\author{
Li Hong Cui \\ No. 6 oil production plant of Daqing Oilfield Co., Ltd. Heilongjiang Daqing 163000
}

\begin{abstract}
With Lamadian Oilfield entering the late stage of ultra-high water cut, the number of thick layers in water drive is becoming less and less, so it is imperative to study the remaining oil in thin difference reservoir. For the thin difference reservoir, the independent off surface reservoir has naturally become an important research object [1]. It is necessary to study the waterflooding condition of the independent outer surface reservoirs to find out the producing law of the thin difference reservoirs at present. In this paper, we mainly use the water washing data of independent outer surface reservoir and core data of sidewall of coring well to find the water flooding interpretation law of independent outer surface reservoir. This paper focuses on the analysis of the characteristics of the electric logging curve of the independent off surface reservoir after water flooding, and summarizes a set of qualitative interpretation methods suitable for the independent off surface reservoir of Lamadian oilfield. This method can improve the accuracy of water flooded layer interpretation and meet the needs of remaining oil potential tapping in the later stage of ultra-high water cut.
\end{abstract}

\section{Study on qualitative interpretation method of water flooding in independent off surface reservoir of Lamadian Oilfield}

\subsection{Analysis of water washing status of independent outer surface reservoir of core well}

It is the most direct and accurate method to determine the watered out condition of oil layer by analyzing the data of water washing of sealed coring. The data of coring wells from 1995 to 2015 were randomly selected and analyzed

(1) According to the statistics of coring data in 2015, weak washing and no washing accounted for $79.0 \%$, while strong washing and medium washing only accounted for $21.0 \%$, of which strong washing only accounted for $4.2 \%$. It shows that the water washing degree of the independent outer surface reservoir in Lamadian oilfield is not high at present, and the weak non water washing is the main, the middle water washing is the second, and the strong water washing is the least.

(2) Compared with the coring well data in 1995 and 2015 , the ratios of strong, medium, weak and no water washing are $4.3 \%, 9.8 \%, 3.8 \%, 82.1 \%$ and $4.2 \%, 16.8 \%$, $0.8 \%$ and $78.2 \%$ respectively, which shows that the water washing degree of independent outer surface reservoir in Lamadian Oilfield has little change.

\subsection{Research on the characteristics of electric logging curve after water flooding of independent off surface reservoir by using sidewall coring data}

Based on the data of 7 coring wells and the experience of water flooded reservoir interpretation in thick oil layer, six logging curves of deep side, microsphere, density, acoustic wave, micro potential and natural potential, which are closely related to water flooded reservoir interpretation, are selected to read their amplitude values and observe their curve forms[2], and table 1 is made to summarize the change characteristics of logging curves after water flooded of independent off surface reservoir. 
Table1. reading table of main electric logging curve of independent reservoir outside the core well

\begin{tabular}{|c|c|c|c|c|c|c|c|c|c|c|}
\hline \multirow[b]{2}{*}{ 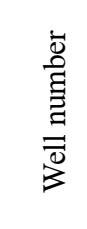 } & \multirow[b]{2}{*}{ 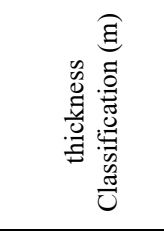 } & \multicolumn{2}{|c|}{ thickness(m) } & \multirow{2}{*}{ 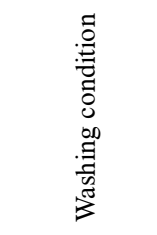 } & \multicolumn{6}{|c|}{ Logging curve reading status } \\
\hline & & 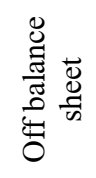 & 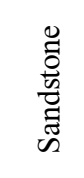 & & $\begin{array}{l}\bar{\pi} \\
\frac{\pi}{0} \\
\frac{\pi}{0} \\
\overline{0} \\
0\end{array}$ & 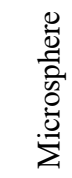 & $\begin{array}{l}\stackrel{\overrightarrow{0}}{0} \\
\stackrel{0}{0} \\
\overrightarrow{0}\end{array}$ & 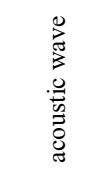 & 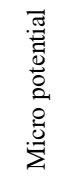 & 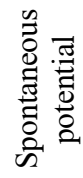 \\
\hline \multirow{7}{*}{$\begin{array}{c}7 \\
\text { wells }\end{array}$} & \multirow{2}{*}{$0.1 \leq \mathrm{h}<0.5$} & 0.30 & 0.04 & Unwashed & 7.9 & 13.3 & 2.30 & 328.3 & 6.8 & 6.9 \\
\hline & & 0.38 & 0.10 & washing & 9.5 & 15.5 & 2.32 & 326.3 & 8.3 & 10.8 \\
\hline & $\begin{array}{l}\text { Difference } \\
\text { value }\end{array}$ & -0.08 & -0.06 & & -2 & -2.2 & -0.02 & 2.1 & -1.5 & -3.9 \\
\hline & \multirow{2}{*}{$0.5 \leq \mathrm{h}<2.0$} & 0.74 & 0.17 & Unwashed & 9.4 & 15.9 & 2.26 & 332.0 & 7.0 & 11.0 \\
\hline & & 0.90 & 0.40 & washing & 8.5 & 15.0 & 2.32 & 315.0 & 6.8 & 10.0 \\
\hline & $\begin{array}{l}\text { Difference } \\
\text { value }\end{array}$ & -0.16 & -0.23 & & 0.9 & 0.9 & -0.06 & 17.0 & 0.2 & 1.0 \\
\hline & Same layer & 0.83 & 0.73 & Same layer & 11.5 & 15.5 & 2.23 & 343.8 & 7.8 & 14.3 \\
\hline \multirow{6}{*}{ 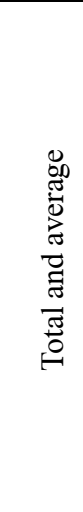 } & \multirow[b]{2}{*}{$0.1 \leq \mathrm{h}<0.5$} & 0.35 & 0.08 & Unwashed & 9.2 & 14.6 & 2.29 & 324.4 & 8.2 & 9.5 \\
\hline & & 0.55 & 0.03 & washing & 10.3 & 15.8 & 2.28 & 321.9 & 8.5 & 14.5 \\
\hline & $\begin{array}{l}\text { Differen-ce } \\
\text { value }\end{array}$ & -0.21 & 0.04 & & -1.1 & -1.2 & 0.01 & 2.4 & -0.3 & -5.0 \\
\hline & \multirow{2}{*}{$0.5 \leq \mathrm{h}<2.0$} & 0.86 & 0.06 & Unwashed & 10.8 & 15.7 & 2.26 & 328.5 & 8.6 & 14.1 \\
\hline & & 0.82 & 0.14 & washing & 10.8 & 16.6 & 2.28 & 325.5 & 8.4 & 15.2 \\
\hline & $\begin{array}{l}\text { Differen-ce } \\
\text { value }\end{array}$ & 0.04 & -0.08 & & 0.0 & -0.9 & -0.02 & 3.0 & 0.3 & -1.2 \\
\hline \multirow{5}{*}{ 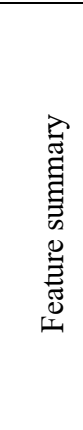 } & \multirow{2}{*}{$0.1 \leq \mathrm{h}<0.5$} & 0.33 & 0.10 & Unwashed & \multirow{2}{*}{ 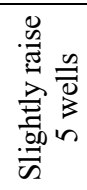 } & \multirow{2}{*}{ 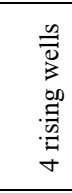 } & \multirow{2}{*}{ 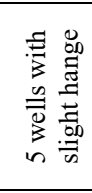 } & \multirow{2}{*}{ 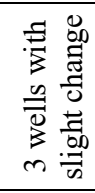 } & $\overline{\overline{0}}$ & \multirow{2}{*}{ 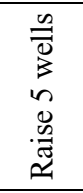 } \\
\hline & & 0.45 & 0 & washing & & & & & క్ & \\
\hline & \multirow{2}{*}{$0.5 \leq \mathrm{h}<2.0$} & 0.85 & 0.10 & Unwashed & \multirow{2}{*}{ 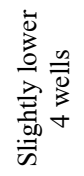 } & \multirow{2}{*}{$\begin{array}{l}\frac{n}{0} \\
\overline{0} \\
5 \\
5 \\
5 \\
0 \\
0\end{array}$} & \multirow{2}{*}{ 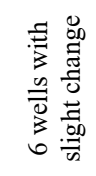 } & \multirow{2}{*}{ 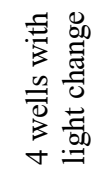 } & $\stackrel{n}{\overline{0}}$ & \multirow{2}{*}{$\begin{array}{l}\overline{\overline{0}} \\
\vdots \\
\bar{\xi} \\
\overline{0} \\
0\end{array}$} \\
\hline & & 0.88 & 0.20 & washing & & & & & ڤే & \\
\hline & Same layer & 0.57 & 0.18 & Same layer & 9.9 & 14.2 & 2.25 & 324.1 & 8.3 & 18.2 \\
\hline
\end{tabular}

It can be seen from these tables that the change rule of logging curve after water flooding of independent off surface reservoir is quite different from that of thick reservoir

(1) For the independent outer surface reservoir with similar density and acoustic time difference curve amplitude, the reservoir with smaller difference of deep lateral and microsphere amplitude is more likely to be flooded. The smaller the difference, the higher the degree of flooding.

(2) For the independent outer surface reservoir with similar density and acoustic time difference curve amplitude, the reservoir with higher resistivity curve (deep lateral and microsphere) is more likely to be flooded by water, and the increase rule of resistivity curve amplitude with the increase of thickness is not changed. The resistivity of $0.1 \mathrm{~m} \leq \mathrm{h}<0.5 \mathrm{~m}$ is obviously increased, while that of $0.5 \mathrm{~m} \leq \mathrm{h}<2.0 \mathrm{~m}$ is decreased, and the former is obviously lower than the latter. This is different from the law of resistivity decrease after water flooding in thick reservoir.

(3) The amplitude of spontaneous potential curve increased obviously. However, the natural potential migration value is a method to judge the watered out of thick reservoir, and the amplitude value is not important.

(4) The amplitude of density, acoustic wave and micropotential curve is stable or unchanged. However, the amplitude of density curve does not change, but the amplitude of acoustic curve will increase.

(5) In the same layer of oil and water, the resistivity 
curve slightly decreases, the density and acoustic curve have no obvious change, and the natural potential curve rises obviously; in the same layer of thick oil and water, the resistivity curve obviously decreases, and the natural potential also rises.

(6) There is not much change in the shape of logging curves after the water flooded and the UN flooded reservoirs outside the independent surface. The thick oil layer is very obvious. The first is that the peak of resistivity curve becomes smooth. The second is the migration value of mudstone baseline of natural potential curve.

\section{The improved method improves the coincidence rate[3] of waterflooding interpretation of independent off surface reservoir}

By using the improved water flooded interpretation method of independent off surface reservoirs, 341 independent off surface reservoirs of 12 core wells were re interpreted. The comparison of the complete and approximate coincidence rates is shown in table 2 .

Table 2. coincidence rate between manual correction results of computer automatic interpretation and core water washing data of independent off surface reservoir

\begin{tabular}{|c|c|c|c|c|c|c|c|c|}
\hline \multirow[b]{2}{*}{$\begin{array}{l}\text { Thickness } \\
\text { grading (m) }\end{array}$} & \multicolumn{2}{|c|}{$\begin{array}{l}\text { Interpretation of core } \\
\text { data }\end{array}$} & \multicolumn{6}{|c|}{ Computer auto interpretation status } \\
\hline & $\begin{array}{c}\text { Washing } \\
\text { level }\end{array}$ & $\begin{array}{c}\text { Number } \\
\text { of } \\
\text { natural } \\
\text { layers }\end{array}$ & 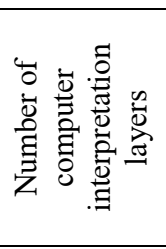 & 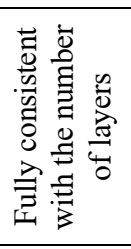 & 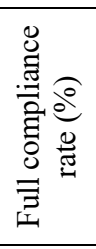 & 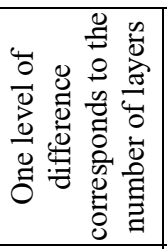 & 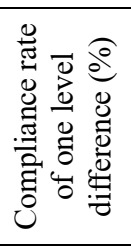 & 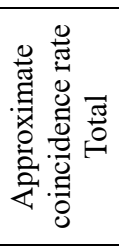 \\
\hline \multirow{4}{*}{$0.1 \leq \mathrm{h} \leq 0.5$} & Unwashed & 212 & 176 & 121 & 42.2 & 7 & 2.4 & 44.6 \\
\hline & Low wash & 15 & 38 & 13 & 4.5 & 8 & 2.8 & 7.3 \\
\hline & $\begin{array}{l}\text { Medium } \\
\text { wash }\end{array}$ & 31 & 53 & 21 & 7.3 & 9 & 3.1 & 10.4 \\
\hline & $\begin{array}{l}\text { High water } \\
\text { wash }\end{array}$ & 12 & 20 & 8 & 2.8 & 4 & 1.4 & 4.2 \\
\hline \multirow{4}{*}{$0.5<\mathrm{h} \leq 1.0$} & Unwashed & 49 & 35 & 31 & 48.4 & 7 & 10.9 & 59.3 \\
\hline & Low wash & 2 & 6 & 2 & 3.1 & 6 & 9.4 & 12.5 \\
\hline & $\begin{array}{l}\text { Medium } \\
\text { wash }\end{array}$ & 7 & 15 & 6 & 9.4 & 3 & 4.7 & 14.1 \\
\hline & $\begin{array}{l}\text { High water } \\
\text { wash }\end{array}$ & 4 & 8 & 3 & 4.7 & 1 & 1.6 & 6.3 \\
\hline \multirow{4}{*}{$\mathrm{h}>1.0$} & Unwashed & 9 & 5 & 4 & 44.4 & 1 & 11.1 & 55.5 \\
\hline & Low wash & 0 & 1 & 0 & 0.0 & 0 & 0.0 & 0.0 \\
\hline & $\begin{array}{l}\text { Medium } \\
\text { wash }\end{array}$ & 0 & 2 & 0 & 0.0 & 0 & 0.0 & 0.0 \\
\hline & $\begin{array}{l}\text { High water } \\
\text { wash }\end{array}$ & 0 & 1 & 0 & 0.0 & 0 & 0.0 & 0.0 \\
\hline \multirow{4}{*}{ Total } & Unwashed & 270 & 216 & 156 & 43.3 & 15 & 4.2 & 47.5 \\
\hline & Low wash & 17 & 45 & 15 & 4.2 & 14 & 3.9 & 8.1 \\
\hline & $\begin{array}{l}\text { Medium } \\
\text { wash }\end{array}$ & 38 & 70 & 27 & 7.5 & 12 & 3.3 & 10.8 \\
\hline & $\begin{array}{l}\text { High water } \\
\text { wash }\end{array}$ & 16 & 29 & 11 & 3.1 & 5 & 1.4 & 4.5 \\
\hline \multicolumn{2}{|c|}{ Total and average } & 341 & 360 & 209 & 58.1 & 46 & 12.8 & 70.9 \\
\hline
\end{tabular}

(1) This method improves the coincidence rate of the interpretation of the UN watered out.The full compliance rate increased from $13.1 \%$ to $43.3 \%, 30$ percentage points higher.

(2) This method reduces the number of first-order coincidence layers from 106 to 46 , which is 1.3 times lower. The rate of poor first-class compliance decreased from $29.4 \%$ to $12.8 \%, 17$ percentage points lower.

(3) This method greatly improves the approximate coincidence rate, from 159 layers to 255 layers, from 
$44.2 \%$ to $70.9 \%, 27$ percentage points higher.

(4) The method can improve the interpretation accuracy of the water flooded layer of the independent off surface reservoir by properly increasing the number of low and middle high water flooded layers.

\section{3 conclusions and suggestions}

(1) The degree of water washing is not high in the independent outer surface reservoir, which is dominated by weak water washing, followed by middle water washing, and the least by strong water washing; the degree of water washing has little change.

(2) The function of judging the water flooded condition by the decrease of resistivity amplitude is decreased, and the function of judging the water flooded condition by the increase of natural potential amplitude is enhanced. The decrease of the amplitude difference between the deep side and the microsphere curve should also be used to judge the electrical logging characteristics of the independent outer surface reservoir after water flooding [4].

(3) The method of water flooded qualitative interpretation of independent off surface reservoir is to improve the accuracy of water flooded interpretation of independent off surface reservoir by properly increasing the number of low and under water flooded interpretation layers and reducing the number of medium and high water flooded layers.

\section{Reference}

1. Gao Dapeng. A development method of independent off surface reservoir in extra high water cut period [J]. Patent of China National Petroleum Corporation, (2015)

2. Chen Minxia. Improvement on interpretation method of reservoir thickness outside the surface [M]. No. 6 oil production plant, (2014)

3. Tang Hong. Study on water flooded interpretation of thin poor reservoirs [J]. Journal of Southwest Petroleum Institute, (2003)

4. Jia Chunyu. Residual oil potential analysis of thin poor reservoir in Lamadian Oilfield [M]. No. 6 oil production plant, (2019) 